\title{
Modified PWM Technique for Harmonic Reduction
}

\author{
Alireza Hoseinpour ${ }^{1}$ and Reza Ghazi ${ }^{2}$ \\ ${ }^{1}$ Sistan \& Baluchestan Regional Electrical Company (SBREC), Zahedan 9817917765, Iran \\ ${ }^{2}$ Ferdowsi University of Mashad, Mashad 9177948974, Iran
}

Correspondence should be addressed to Alireza Hoseinpour, ali_reza_2642@yahoo.com

Received 12 March 2012; Accepted 8 April 2012

Academic Editors: H. A. Alzaher, A. R. Seidel, and E. Tlelo-Cuautle

Copyright (C) 2012 A. Hoseinpour and R. Ghazi. This is an open access article distributed under the Creative Commons Attribution License, which permits unrestricted use, distribution, and reproduction in any medium, provided the original work is properly cited.

This paper presents a Shunt Active Filter (SAF) based on the Variable Index Pulse Width Modulation approach. In the proposed method of Pulse Width Modulation (PWM), the triangular wave is derived by integration of the reference signals. This method introduces two basic advantages; the first one is that the triangular signal contains the information of the signal to be obtained in output and the second advantage is that its amplitude is varied in proportion to the amplitude of the reference signal. Therefore, in this PWM method, the modulation index is varied according to the variation of the reference signal, so it is termed as Variable Index Pulse Width Modulation. In order to demonstrate the validity of the proposed method, the obtained simulation results are compared with results of the Space Vector Modulation (SVM) approach. Furthermore, it is shown that in the case of nonsinusoidal voltages, the SAF with the proposed control strategy can provide the filtering action. This method is quite easy to implement and requires lower circuitry. The results show that the proposed method can satisfy the IEEE-519 standard regarding the reduction of harmonics.

\section{Introduction}

Nonlinear loads such as adjustable speed drives, power supplies for various electronic equipments are the origin of both current and voltage harmonics production in the distribution system leading to the power quality problem. In response to the power quality problem, IEEE 519 and IEC EN 61000-3 standards specify regulations governing harmonic compliance. Numerous active filters are introduced as effective means to meet the harmonic standards beside the passive filters that have been proposed [1-4]. The SAF has become a mature technology in recent years. The operation principle of an active filter is based on PWM or SVM three-phase inverter to generate nonsinusoidal currents to meet harmonic current requirement of the nonlinear load. Many various configurations, control strategies, and applications of active filters are offered in the literature [5-7]. The SAF performs the filtering action by injecting harmonic components which cancel those from the load, thereby the line current becomes free of harmonics [8]. In filter design and its application, the methods for extraction of the harmonics from line current and determination of the filter reference current play an important and crucial role. Indeed, accuracy and speed of the SAF response are related to this point [9-11]. Time domain and frequency domain are two well-known methods for generation of reference current [12-15]. Time domain methods are based on measurements and transformation of three-phase quantities such as d-q or p-q transformation, whereas the frequency methods are based on the Fast Fourier Transformation (FFT). The main advantage of time domain methods is their fast response. On the other side, frequency domain methods can provide accurate individual and multiple harmonic detection of load current. Time domain methods, such as, instantaneous reactive power depend on source voltage harmonic. This fact is proved with mathematical equations. With regard to the compensation objectives, the control strategy and the method for extracting the nonactive load currents references are determined [815]. The purpose of this paper is to compensate the harmonic current using the frequency domain method of compensation in which all harmonic current components are targeted and eliminated. In this paper a novel PWM technique with the property of variable index based on the integral of reference current is suggested and applied on a SAF. To 


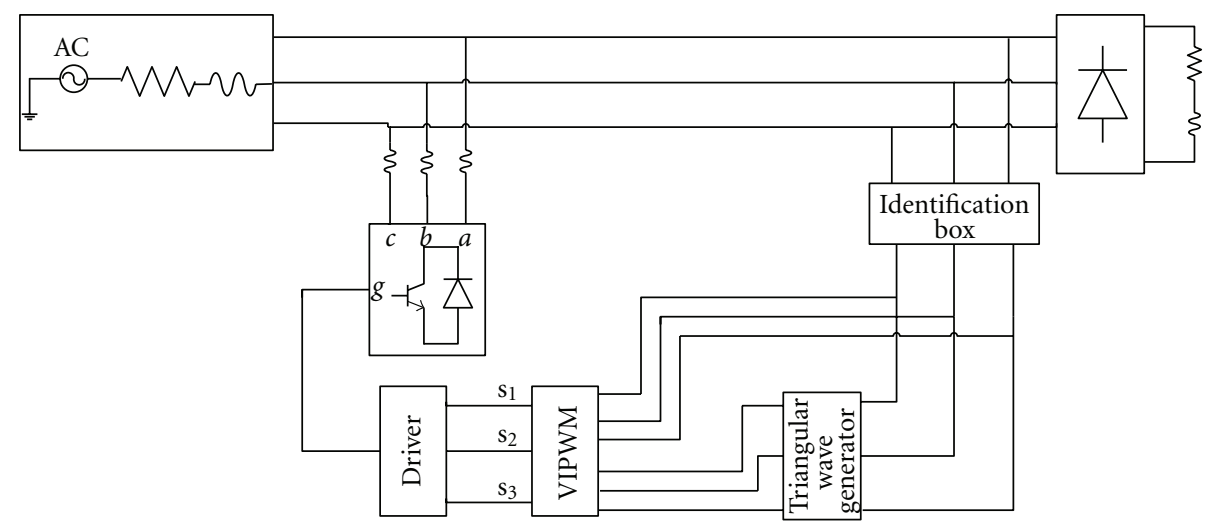

FIgURE 1: Configuration of SAF.

demonstrate its performance and superiority the obtained results are compared with [16] in which the SVM technique based on Hysteresis Current Controller (HCC) is used. The paper is organized as follows. Section 2 defines the configuration and control system of SAF. The proposed modified PWM technique is introduced in Section 3. Section 4 is devoted to the application of SAF on a sample circuit with a nonlinear load considering sinusoidal and nonsinusoidal sources. The simulation results are presented in this section, and the necessary comparison has been made to validate its superiority and performance. Conclusions are given in Section 5.

\section{Shunt Active Filter}

The SAF configuration is shown in Figure 1 which consists of identification, modulation, and inverter sections.

The reference signal is generated in the identification section. This signal defines the current that should be produced by the three-phase inverter of SAF. There are two methods for generating the reference signal: time domain and frequency domain. The time domain methods, such as, $\mathrm{d}-\mathrm{q}$ transformation (or synchronous rotating reference frame), $\mathrm{p}-\mathrm{q}$ transformation (or instantaneous reactive power), and symmetrical components transformation are based on measurements and transformation of the threephase quantities.

The main advantage of the time domain methods over the frequency domain methods which are based on the Fast Fourier Transformation (FFT) is their fast responses. However, the frequency domain methods provide accurate individual and multiple harmonic load currents detection [10]. Time domain methods, such as, instantaneous reactive power method depend on the source voltage harmonics. This matter is proved using the mathematical equations. In this theory voltages and currents are measured in $a b c$ frame, then are transformed into orthogonal frame as follows.

$$
\left[\begin{array}{l}
v_{\alpha} \\
v_{\beta} \\
v_{o}
\end{array}\right]=\sqrt{\frac{2}{3}}\left[\begin{array}{ccc}
1 & -0.5 & -0.5 \\
0 & \frac{-\sqrt{3}}{2} & \frac{\sqrt{3}}{2} \\
\frac{1}{\sqrt{2}} & \frac{1}{\sqrt{2}} & \frac{1}{\sqrt{2}}
\end{array}\right]\left[\begin{array}{l}
v_{a} \\
v_{b} \\
v_{c}
\end{array}\right],
$$

$$
\left[\begin{array}{c}
i_{\alpha} \\
i_{\beta} \\
i_{o}
\end{array}\right]=\sqrt{\frac{2}{3}}\left[\begin{array}{ccc}
1 & -0.5 & -0.5 \\
0 & \frac{-\sqrt{3}}{2} & \frac{\sqrt{3}}{2} \\
\frac{1}{\sqrt{2}} & \frac{1}{\sqrt{2}} & \frac{1}{\sqrt{2}}
\end{array}\right]\left[\begin{array}{c}
i_{a} \\
i_{b} \\
i_{c}
\end{array}\right] .
$$

In new frame the powers are calculated by

$$
\left[\begin{array}{c}
P \\
q \\
P_{o}
\end{array}\right]=\left[\begin{array}{ccc}
v_{\alpha} & v_{\beta} & 0 \\
-v_{\beta} & v_{\alpha} & 0 \\
0 & 0 & v_{o}
\end{array}\right]\left[\begin{array}{c}
i_{\alpha} \\
i_{\beta} \\
i_{0}
\end{array}\right] .
$$

These powers comprise $\mathrm{dc}$ and ac components. If the aim is to compensate the line current harmonics, the compensator should generate the ac terms. Therefore, the currents of SAF are obtained which can be converted into $a b c$ frame.

$$
\begin{gathered}
{\left[\begin{array}{c}
i_{\alpha}^{*} \\
i_{\beta}^{*} \\
i_{0}^{*}
\end{array}\right]=\left[\begin{array}{ccc}
v_{\alpha} & v_{\beta} & 0 \\
-v_{\beta} & v_{\alpha} & 0 \\
0 & 0 & v_{o}
\end{array}\right]^{-1}\left[\begin{array}{c}
-P_{\mathrm{ac}} \\
-q_{\mathrm{ac}} \\
-P_{o \mathrm{ac}}
\end{array}\right],} \\
{\left[\begin{array}{c}
i_{a}^{*} \\
i_{b}^{*} \\
i_{c}^{*}
\end{array}\right]=\left\{\sqrt{\frac{2}{3}}\left[\begin{array}{ccc}
1 & -0.5 & -0.5 \\
0 & \frac{-\sqrt{3}}{2} & \frac{\sqrt{3}}{2} \\
\frac{1}{\sqrt{2}} & \frac{1}{\sqrt{2}} & \frac{1}{\sqrt{2}}
\end{array}\right]\right\}^{-1}\left[\begin{array}{c}
i_{\alpha}^{*} \\
i_{\beta}^{*} \\
i_{0}^{*}
\end{array}\right] .}
\end{gathered}
$$

Although this approach provides a good response when the source is sinusoidal, but it does not for nonsinusoidal sources. Generally, the voltage and current in nonsinusoidal sources contain harmonics given by

$$
\begin{aligned}
& v_{a}=\sum_{n=1}^{\infty} \sqrt{2} V_{n} \sin \left(n \omega t+\psi_{n}\right), \\
& v_{b}=\sum_{n=1}^{\infty} \sqrt{2} V_{n} \sin \left(n \omega t+120+\psi_{n}\right), \\
& v_{c}=\sum_{n=1}^{\infty} \sqrt{2} V_{n} \sin \left(n \omega t-120+\psi_{n}\right),
\end{aligned}
$$




$$
\begin{aligned}
& i_{a}=\sum_{n=1}^{\infty} \sqrt{2} I_{n} \sin \left(n \omega t-\phi_{n}\right), \\
& i_{b}=\sum_{n=1}^{\infty} \sqrt{2} I_{n} \sin \left(n \omega t-\phi_{n}+120\right), \\
& i_{c}=\sum_{n=1}^{\infty} \sqrt{2} I_{n} \sin \left(n \omega t-\phi_{n}-120\right) .
\end{aligned}
$$

These voltages and currents are transformed into orthogonal frame which can be expressed as positive, negative, and zero sequences by (6)

$$
\begin{aligned}
& v_{\alpha}=\sqrt{3} \sum_{n=1}^{\infty} V_{n}^{+} \sin \left(n \omega t+\psi_{n}^{+}\right)+V_{n}^{-} \sin \left(n \omega t+\psi_{n}^{-}\right), \\
& v_{\beta}=\sqrt{3} \sum_{n=1}^{\infty}-V_{n}^{+} \cos \left(n \omega t+\psi_{n}^{+}\right)+V_{n}^{-} \cos \left(n \omega t+\psi_{n}^{-}\right), \\
& v_{o}=\sqrt{6} \sum_{n=1}^{\infty} V_{n}^{o} \sin \left(n \omega t+\psi_{n}^{0}\right), \\
& i_{\alpha}=\sqrt{3} \sum_{n=1}^{\infty}\left(I_{n}^{+} \sin \left(n \omega t-\phi_{n}^{+}\right)+I_{n}^{-} \sin \left(n \omega t-\phi_{n}^{-}\right)\right), \\
& i_{\beta}=\sqrt{3} \sum_{n=1}^{\infty}\left(-I_{n}^{+} \cos \left(n \omega t-\phi_{n}^{+}\right)+I_{n}^{-} \cos \left(n \omega t-\phi_{n}^{-}\right)\right), \\
& i_{o}=\sqrt{3} \sum_{n=1}^{\infty}\left(I_{n}^{o} \sin \left(n \omega t-\phi_{n}^{0}\right)\right) .
\end{aligned}
$$

The power components are obtained from (6), and (3) as

$$
\begin{array}{r}
P=3 \sum_{i=1}^{\infty} \sum_{j=1}^{\infty}\left\{V_{j}^{+} I_{i}^{+} \cos \left((i-j) \omega t+\phi_{i}^{+}-\psi_{j}^{+}\right)\right. \\
+V_{j}^{-} I_{i}^{-} \cos \left((i-j) \omega t+\phi_{i}^{-}-\psi_{j}^{-}\right) \\
-V_{j}^{+} I_{i}^{-} \cos \left((i+j) \omega t+\phi_{i}^{-}+\psi_{j}^{+}\right) \\
\left.-V_{j}^{-} I_{i}^{+} \cos \left((i+j) \omega t+\phi_{i}^{+}+\psi_{j}^{-}\right)\right\}, \\
q=3 \sum_{i=1}^{\infty} \sum_{j=1}^{\infty}\left\{\begin{array}{r}
+ \\
+
\end{array} I_{i}^{+} \sin \left((i-j) \omega t+\phi_{i}^{+}-\psi_{j}^{+}\right)\right. \\
+V_{j}^{-} I_{i}^{-} \sin \left((i-j) \omega t+\phi_{i}^{-}-\psi_{j}^{-}\right) \\
+V_{j}^{+} I_{i}^{-} \sin \left((i+j) \omega t+\phi_{i}^{-}+\psi_{j}^{+}\right) \\
\left.-V_{j}^{-} I_{i}^{+} \sin \left((i+j) \omega t+\phi_{i}^{+}+\psi_{j}^{-}\right)\right\}, \\
P_{o}=3 \sum_{i=1}^{\infty} \sum_{j=1}^{\infty} V_{j}^{o} I_{j}^{o}\left\{\cos \left((i-j) \omega t+\phi_{i}^{o}-\psi_{j}^{o}\right)\right. \\
\left.-\cos \left((i+j) \omega t+\phi_{i}^{o}+\psi_{j}^{o}\right)\right\} .
\end{array}
$$

The dc terms are extracted from (7) and given by (8)

$$
\begin{aligned}
& P_{\mathrm{dc}}=3 \sum_{n=1}^{\infty} V_{n}^{+} I_{n}^{+} \cos \left(\phi_{n}^{+}-\psi_{n}^{+}\right)+V_{n}^{-} I_{n}^{-} \cos \left(\phi_{n}^{-}-\psi_{n}^{-}\right), \\
& q_{\mathrm{dc}}=3 \sum_{n=1}^{\infty}-V_{n}^{+} I_{n}^{+} \sin \left(\phi_{n}^{+}-\psi_{n}^{+}\right)+V_{n}^{-} I_{n}^{-} \cos \left(\phi_{n}^{-}-\psi_{n}^{-}\right), \\
& p_{o_{\mathrm{dc}}}=3 \sum_{n=1}^{\infty} V_{n}^{o} I_{n}^{o} \cos \left(\phi_{n}^{o}-\psi_{n}^{o}\right) .
\end{aligned}
$$

It can be seen from (8) that harmonics components are also available in the dc power term; it means that compensation of the ac terms is not sufficient to reduce harmonics. Therefore, instantaneous reactive power theory is not suitable where source is non sinusoidal. The method used in this paper is a frequency domain approach based on Band Reject Filter (BRF). In this approach, the line current signal is passed through a BRF having a center frequency equal to power system fundamental frequency. The output signal contains all harmonics except the fundamental harmonic, so it can be a suitable reference signal for compensation. Moreover, the BRF method does not require any voltage sensor, in contrast to the instantaneous reactive power method in which three voltage sensors are needed, so it can be more economical.

In the next section a new method of modulation is described and compared with the previous method.

\section{Variable Index Pulse Width Modulation}

In all previously developed SAFs in which the PWM techniques are used, the reference signal is compared with the triangular signal. Such triangular signals have no information. However, in the proposed method the triangular signal is derived from the integral of reference signal so it will be an intelligent signal and has the following advantages. The obtained triangular signal contains the information related to the output signal and also its amplitude will vary in proportion to the amplitude of the reference signal. In fact, the modulation index changes regarding the amplitude of the reference signal, hence it is termed (VIPWM). The procedure of this type of modulation for phase a (leg q1\&q4) in Figure 2 is described as follows.

For generation of a triangular signal we need an integrator with reset capability. According to Figure 3, in the positive half cycle at first, the integral of the reference current is performed, then the output of the integrator which is the triangular wave, compared with the reference current. So long as the reference current is greater than the integrator output, transistor $\mathrm{q}_{1}$ is on and transistor $\mathrm{q}_{4}$ is off. When these two signals are equal, the integrator becomes reset and as long as the integrator output is zero, $\mathrm{q}_{1}$ is off and $\mathrm{q}_{4}$ is on. When output begins to increase $\mathrm{q}_{1}$ starts to conduct and $\mathrm{q}_{4}$ ceases. This process is continued up to the end of the positive half cycle.

However, during the negative half cycle, as long as the integrator output is greater than the reference signal, $\mathrm{q}_{4}$ conducts and $\mathrm{q}_{1}$ does not. When two signals are equal, the 


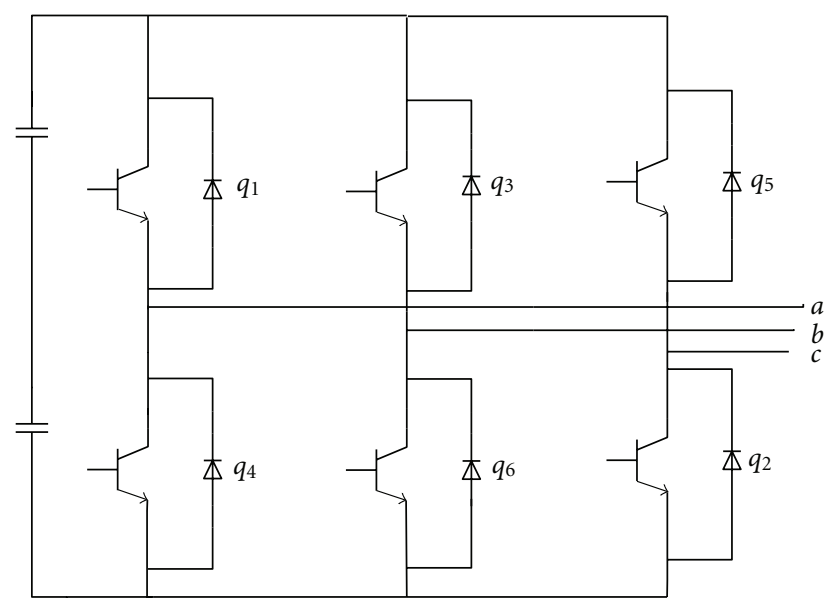

FIgURE 2: The structure of three-phase inverter.

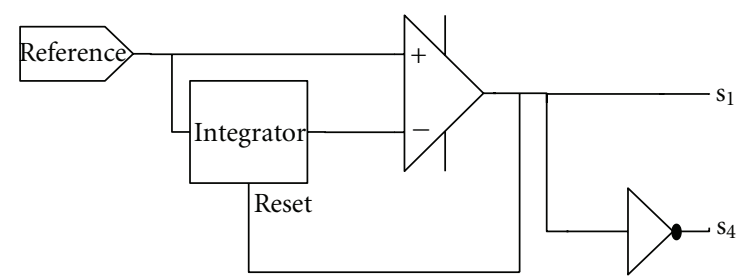

FIgURE 3: Configuration of circuitry for transistor driving.

integrator becomes reset and as long as the integrator output is zero $\mathrm{q}_{1}$ is on and $\mathrm{q}_{4}$ is off. When the integrator output decreases from zero $\mathrm{T}_{4}$ begins to conduct and $\mathrm{T}_{1}$ ceases.

The sine wave, triangular wave and the required signal for driving the transistor q1 corresponding to PWM with a Constant Index Pulse Width Modulation (CIPWM) that $m=$ 0.9 are shown in Figure 4. The similar plots for VIPWM are shown in Figure 5.

\section{Simulation Result}

To show the ability of the SAF under the proposed control strategy, two cases have been simulated. In the first case, the load is nonlinear and the source is sinusoidal, while in the second case the source is non sinusoidal.

4.1. Sinusoidal Source. To evaluate the performance of the VIPWM technique it is applied on a three-phase SAF using MATLAB Simulink and PSIM software. To demonstrate its ability in reducing the harmonic components from line current, a bridge rectifier with an RL circuit is considered as a nonlinear load. The line current without SAF is shown in Figure 6(a). The line current frequency spectra can be calculated using the following equations in which the amplitude of the peak current considered to be equal to $\left( \pm I_{a}\right)$, that is, the small variations in peak are neglected. So we have

$$
\begin{aligned}
i_{1}(t) & =a_{0}+\sum_{n=1}^{\infty}\left[a_{n} \cos (n \omega t)+b_{n} \sin (n \omega t)\right], \\
a_{0} & =I_{\mathrm{dc}}=\frac{1}{2 \pi} \int_{0}^{2 \pi} i_{1}(t) d(\omega t)=0,
\end{aligned}
$$

$$
\begin{aligned}
a_{n}(t)= & \frac{1}{\pi} \int_{0}^{2 \pi} i_{l}(t) \cos (n \omega t) d(\omega t) \\
= & \frac{1}{\pi}\left[\int_{\pi / 6}^{5 \pi / 6} I_{a} \cos (n \omega t) d(\omega t)\right. \\
& \left.-\int_{7 \pi / 6}^{11 \pi / 6} I_{a} \cos (n \omega t) d(\omega t)\right]=0, \\
b_{n}(t)=\frac{1}{\pi} \int_{0}^{2 \pi} i_{l}(t) \sin (n \omega t) d(\omega t) & \frac{1}{\pi}\left[\int_{\pi / 6}^{5 \pi / 6} I_{a} \cos (n \omega t) d(\omega t)\right. \\
& \left.-\int_{7 \pi / 6}^{11 \pi / 6} I_{a} \cos (n \omega t) d(\omega t)\right] \Longrightarrow
\end{aligned}
$$

$$
b_{n}(t)=\left\{\begin{array}{cc}
0 & \text { if } n=2 k \\
0 & \text { if } n=3 k \\
\frac{4 I_{a}}{n \pi} \sin \left(\frac{n \pi}{3}\right) & \text { otherwise. }
\end{array}\right.
$$

According to (9) the amplitude of 2 nd and 3rd harmonics and their multiples are zero but there exist other harmonics. The line current frequency spectra are shown in Figure 6(b). It is clear from this figure that the total harmonic distortion (THD) is equal to $28.56 \%$ which is very high, so according to IEEE 519 standard to it should be reduced.

To do so, a SAF with the proposed control system is employed. The compensator desirable current and its harmonic spectra are shown in Figures 7(a) and 7(b), respectively. The line current and its harmonic spectra after compensation by CIPWM are shown in Figures 8(a) and 8(b), respectively. The line current and its harmonic spectra compensated by VIPWM are also shown in Figures 9(a) and 9(b), respectively. It can be seen from these figures that the THD of CIPWM is $8.06 \%$ and that of VIPWM is $4.02 \%$. So in this respect the VIPWM is superior to CIPWM. To show the ability of the proposed method, a comparison is made with result of [16], where the SVM-based HCC is used and the obtained THD is equal to $5.32 \%$ which still does not satisfy the IEEE519 standard, while the proposed method of the present paper does. Furthermore, its implementation is easy and requires lower costs and circuitry.

4.2. Nonsinusoidal Source. In most of research works found in the literature which are dealing with the problem of active filtering, the source is considered to be pure sinusoidal, whereas due to the wide speared nonlinear loads in modern electric systems, this assumption is no longer valid. It is shown that the proposed method of PWM has the ability to tackle the problem of nonsinusoidal voltage. For this purpose a triangular source voltage is applied on the test system. This input voltage and its frequency spectra are shown in Figures 10(a) and 10(b), respectively. According to the frequency spectra the THD of this signal is equal to $12.12 \%$. The line current and its frequency spectra are also shown in Figures 11(a) and 11(b). The THD of line current before compensation is $28.31 \%$. The line current 


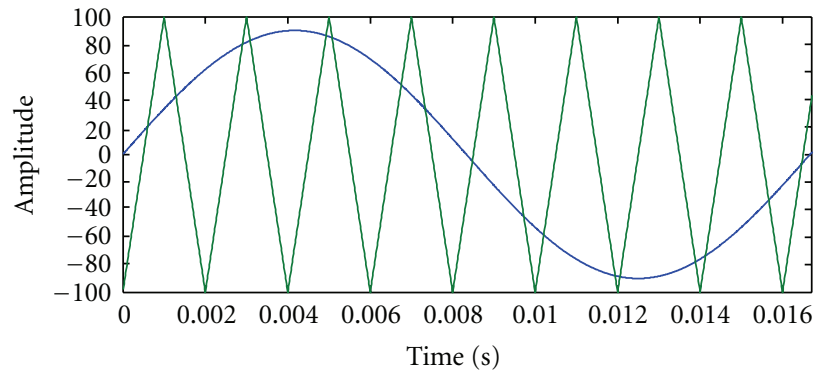

(a)

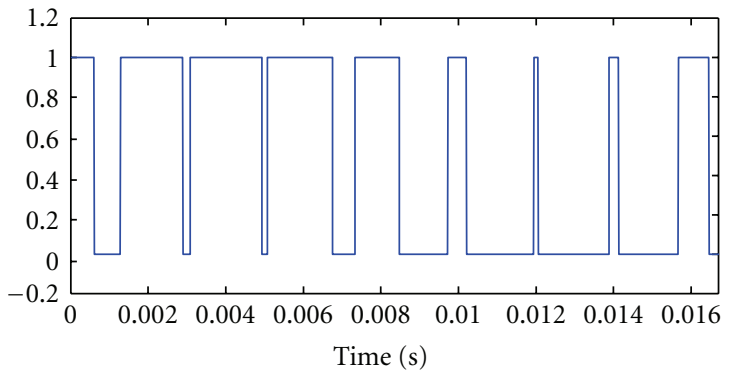

(b)

FIGURE 4: Modulation with constant index $(m=0.9)$. (a) Sine wave and triangular wave. (b) Logic signal for driving transistor $\mathrm{T}_{1}$.

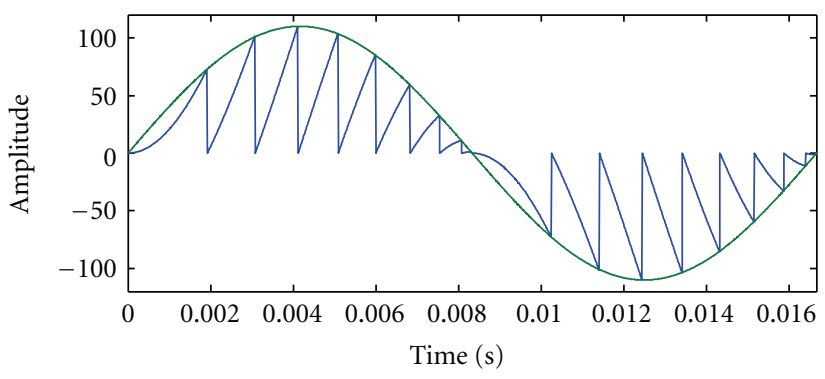

(a)

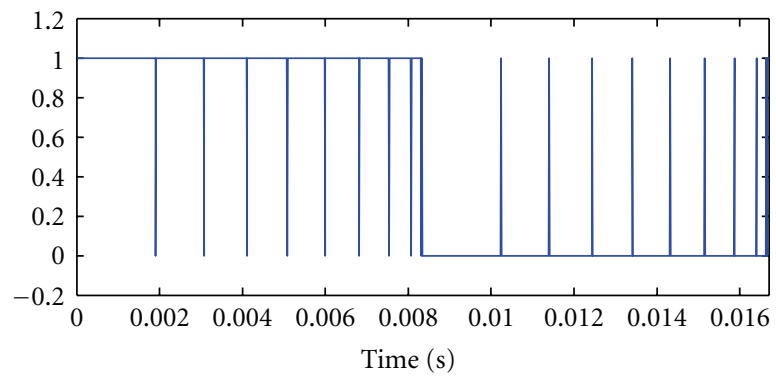

(b)

FIGURE 5: Modulation with variable index. (a) Sine wave and triangular wave. (b) Logic signal for driving transistor $\mathrm{T}_{1}$.

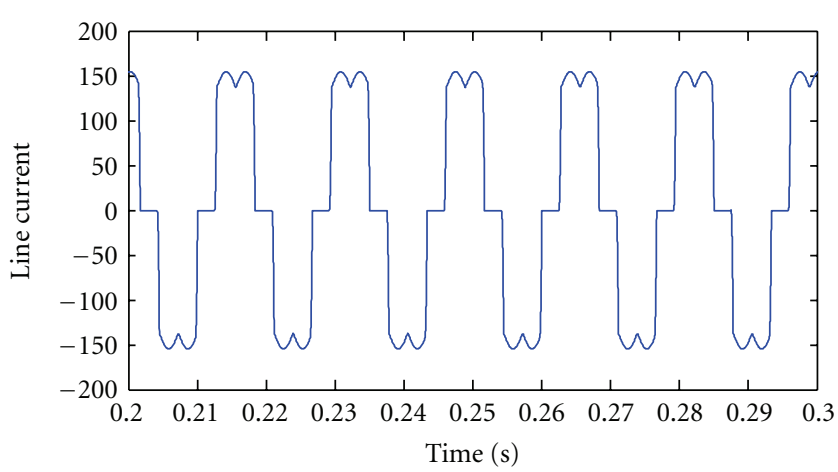

(a)

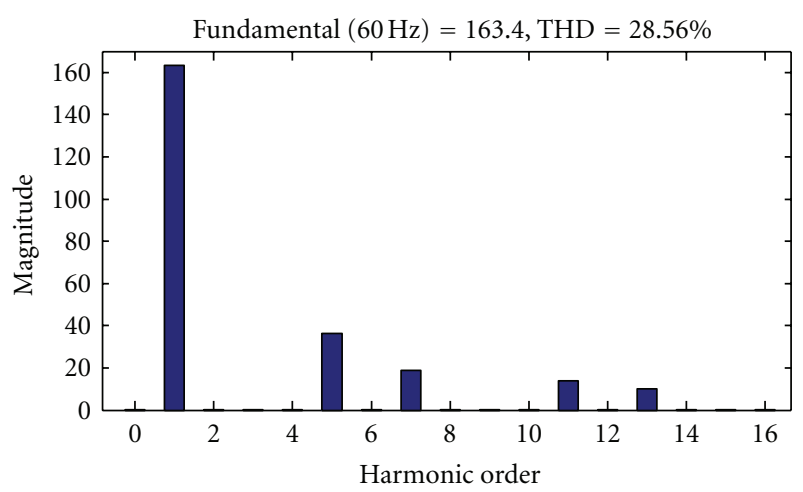

(b)

FIGURE 6: Line current without SAF for nonlinear load. (a) Original current waveform. (b) Current frequency spectra.

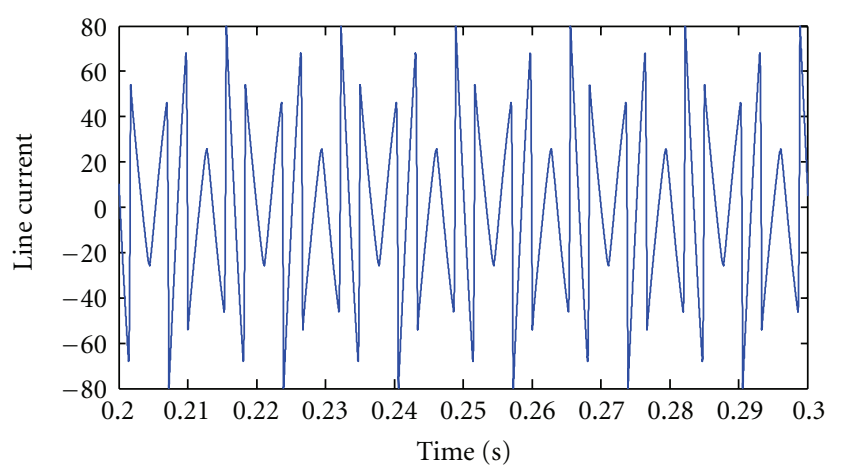

(a)

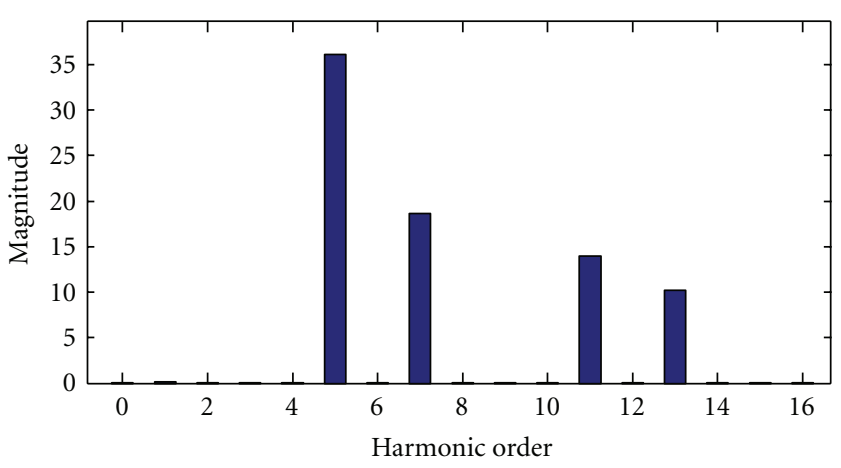

(b)

FIGURE 7: Desired current to be provided by SAF. (a) Original current waveform. (b) Current frequency spectra. 


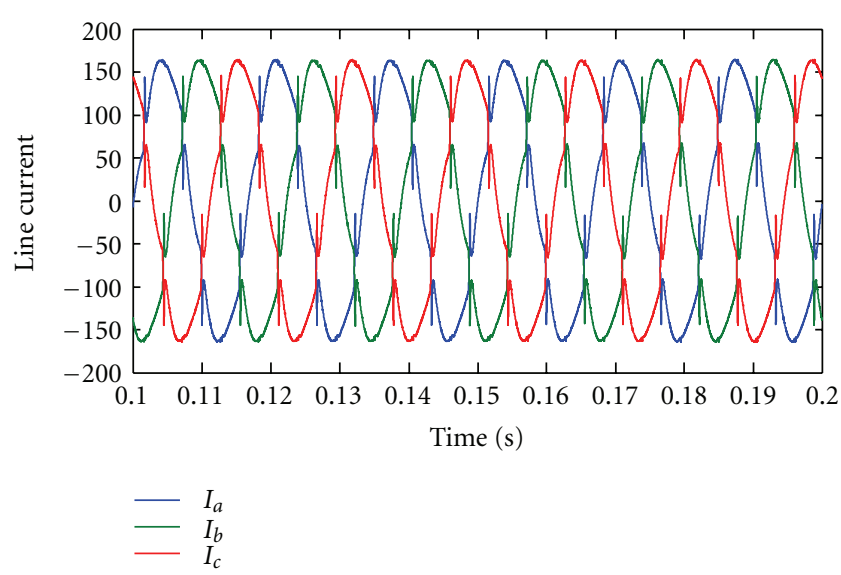

(a)

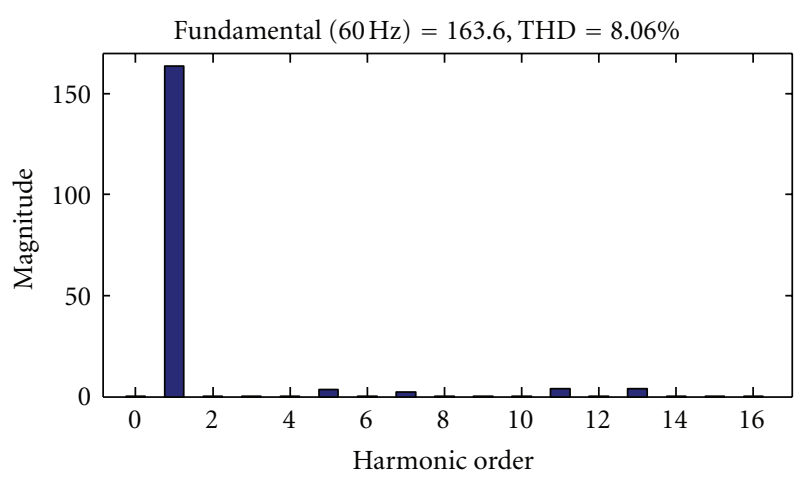

(b)

FIGURE 8: Line current with SAF operated by CIPWM method. (a) Original current waveform. (b) Current frequency spectra.

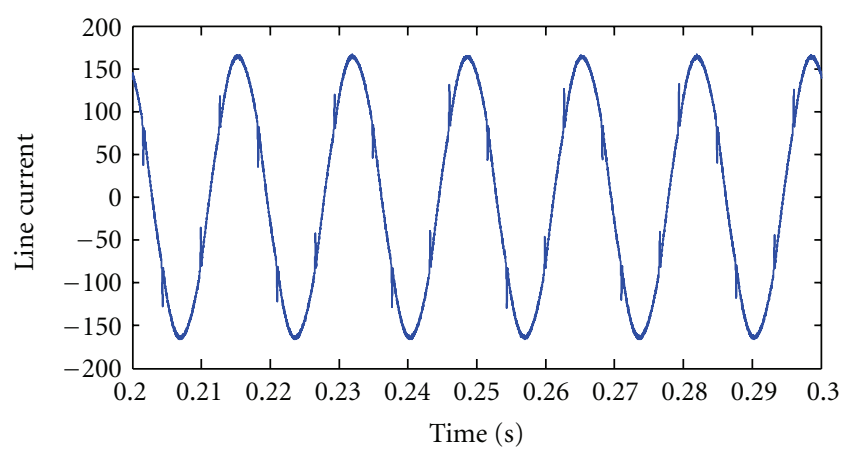

(a)

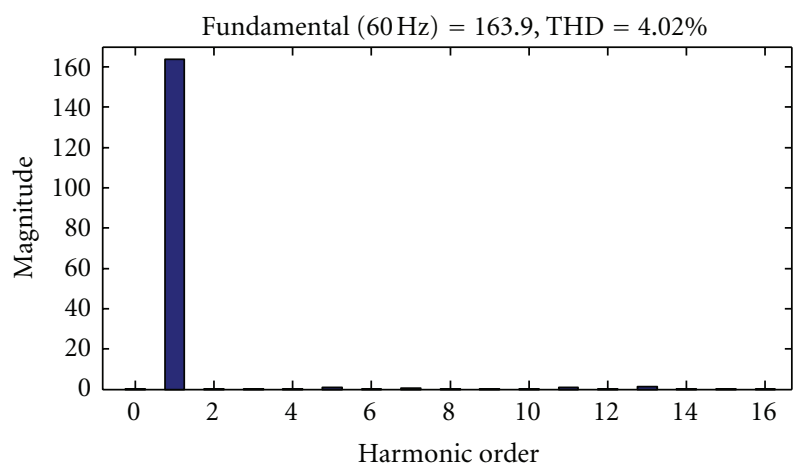

(b)

FIGURE 9: Line current with SAF operated by VIPWM method. (a) Original current waveform. (b) Current frequency spectra.

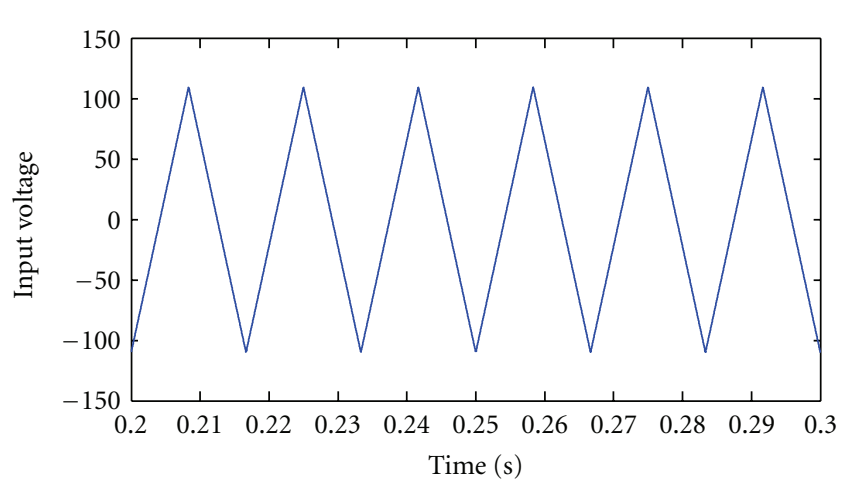

(a)

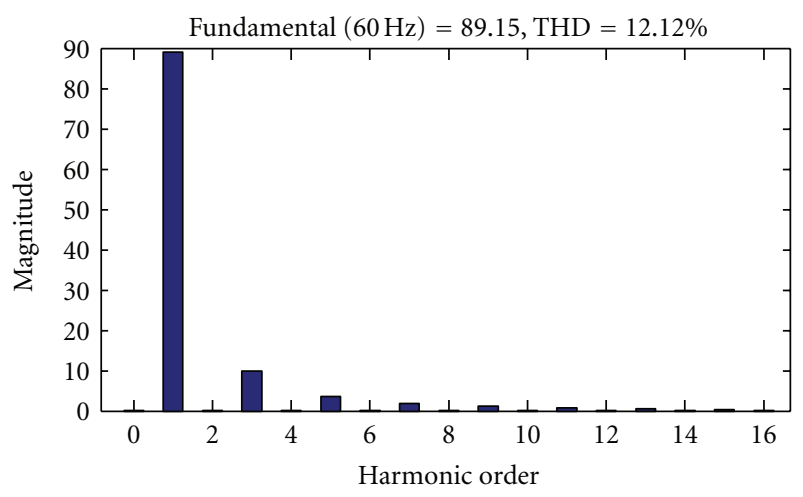

(b)

FIGURE 10: Input voltage without SAF. (a) Voltage waveform. (b) Frequency spectra.

and its frequency spectra after compensation with CIPWM and VIPWM are shown in Figures 12(a) and 12(b) and Figures 13(a) and 13(b), respectively. In the first system the THD is $8.28 \%$ whereas THD of the compensated line current with VIPWM is equal to $4.14 \%$. It is clear from these observations that the THD is greatly reduced. Hence, the SAF can properly work for both cases, but the second one is preferred.
Hence, the proposed SAF can properly operate in both cases.

\section{Conclusion}

In this paper, the ability and the performance of shunt active filters (SAFs) are improved by proposing a new type of PWM 


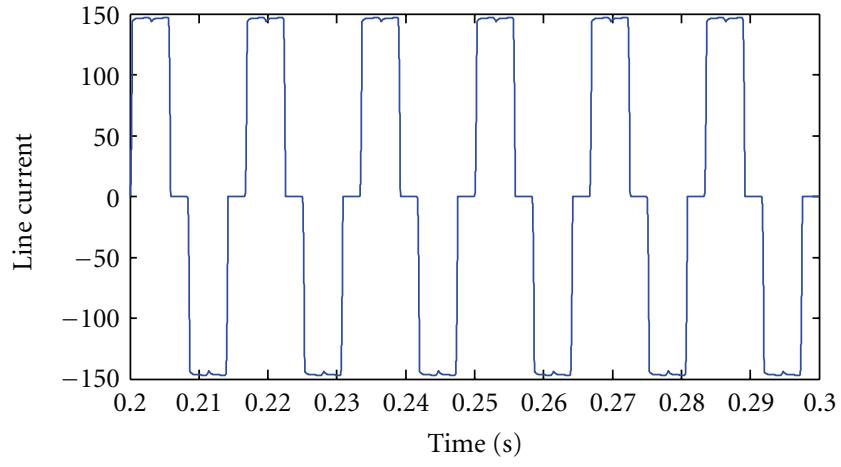

(a)

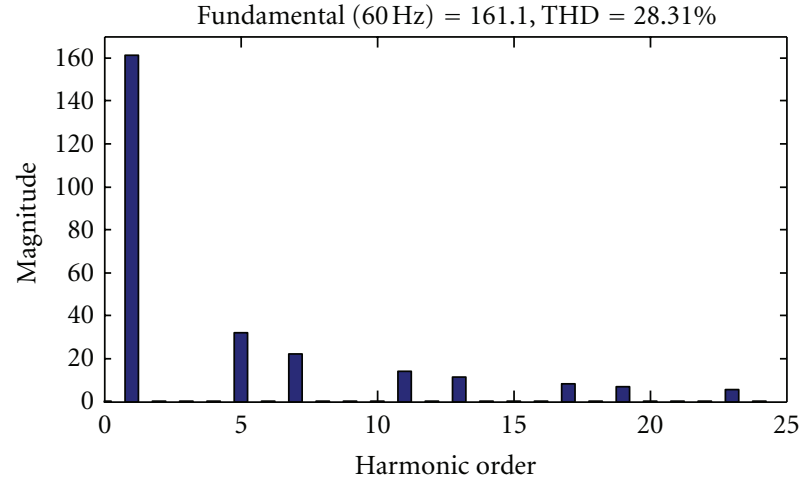

(b)

FIGURE 11: Line current without SAF for nonlinear load. (a) Original current waveform. (b) Current frequency spectra.

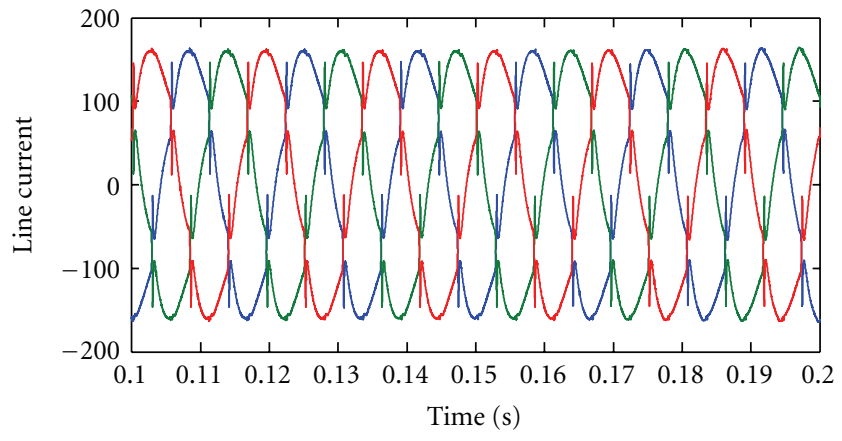

(a)

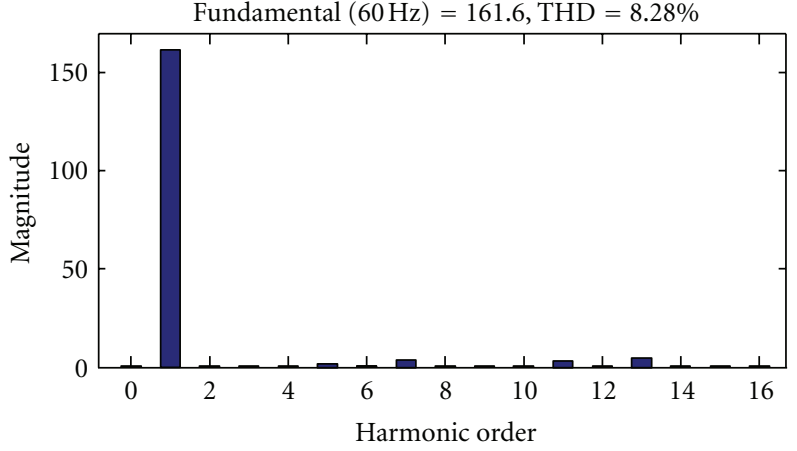

(b)

FIGURE 12: Line current with SAF operated by CIPWM method (a) Original current waveform. (b) Current frequency spectra.

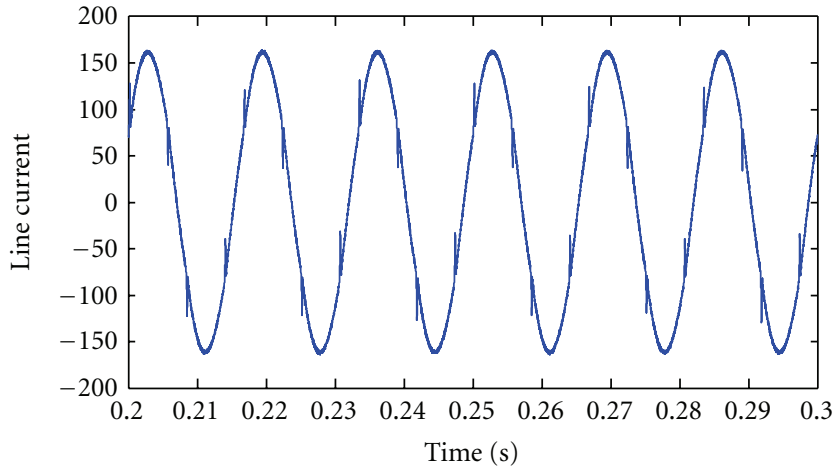

(a)

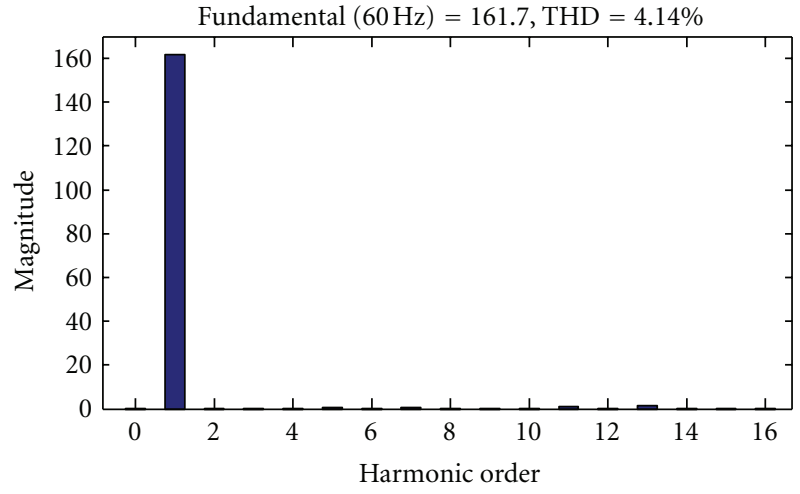

(b)

FIGURE 13: Line current with SAF operated by VIPWM method (a) Original current waveform. (b) Current frequency spectra.

technique. In our proposed PWM method, the modulation index varies according to the variations of the reference signals, so it is termed as Variable Index Pulse Width Modulation (VIPWM) technique. The simulation results show that the SAF under this PWM technique can greatly remove the harmonic components from line current to satisfy the requirement of IEEE standard. The obtained results also show that this technique can do the filtering action in the case of nonsinusoidal voltage source. This method is easy to implement with lower cost and circuitry.

\section{Appendix}

In nonlinear load: $R=1 \Omega, L=0.3 \mathrm{mH}$. The magnitude of sinusoidal and nonsinusoidal source is $110 \mathrm{~V}$ and their frequency is $60 \mathrm{~Hz}$. 


\section{References}

[1] V. F. Corasaniti, M. B. Barbieri, P. L. Arnera, and M. I. Valla, "Hybrid active filter for reactive and harmonics compensation in a distribution network," IEEE Transactions on Industrial Electronics, vol. 56, no. 3, pp. 670-677, 2009.

[2] S. Rahmani, A. Hamadi, N. Mendalek, and K. Al-Haddad, "A new control technique for three-phase shunt hybrid power filter," IEEE Transactions on Industrial Electronics, vol. 56, no. 8, pp. 2904-2915, 2009.

[3] N. He, D. Xu, and L. Huang, "The application of particle swarm optimization to passive and hybrid active power filter design," IEEE Transactions on Industrial Electronics, vol. 56, no. 8, pp. 2841-2851, 2009.

[4] V. F. Corasaniti, M. B. Barbieri, P. L. Arnera, and M. I. Valla, "Hybrid power filter to enhance power quality in a mediumvoltage distribution network," IEEE Transactions on Industrial Electronics, vol. 56, no. 8, pp. 2885-2893, 2009.

[5] A. Hoseinpour and R. Ghazi, "Three phase active filter manufacturing correction with economy consideration for sinusoidal and none sinusoidal sources," in Proceedings of the 1st Power Quality Conferance (PQC '10), September 2010.

[6] S. Round, H. Laird, R. Duke, and A. Gardmer, "The transient and steady state performance of a shunt active filter using measured site data," in Proceedings of the International Conjewnce on Harmonics and Qualiv of Power, pp. 395-400, 1998.

[7] J. H. C. Pretonus, I. D. Vn Wyk, and P. H. Swart, "Evaluation of the effectiveness of passive and dynamic filters for non active power in a large industrial plant," in Proceedings of the International Conjer-ence on Hannonics and Quality of Power, pp. 331-336, 1998.

[8] M. K. Mishra and K. Karthikeyan, "An investigation on design and switching dynamics of a voltage source inverter to compensate unbalanced and nonlinear loads," IEEE Transactions on Industrial Electronics, vol. 56, no. 8, pp. 2802-2810, 2009.

[9] K. Drobnic, M. Nemec, D. Nedeljkovic, and V. Ambrozic, "Predictive direct control applied to AC drives and active power filter," IEEE Transactions on Industrial Electronics, vol. 56, no. 6, pp. 1884-1893, 2009.

[10] M. A. M. Radzi and N. A. Rahim, "Neural network and bandless hysteresis approach to control switched capacitor active power filter for reduction of harmonics," IEEE Transactions on Industrial Electronics, vol. 56, no. 5, pp. 1477-1484, 2009.

[11] M. Cirrincione, M. Pucci, G. Vitale, and A. Miraoui, "Current harmonic compensation by a single-phase shunt active power filter controlled by adaptive neural filtering," IEEE Transactions on Industrial Electronics, vol. 56, no. 8, pp. 3128-3143, 2009.

[12] B. Singh and J. Solanki, "An implementation of an adaptive control algorithm for a three-phase shunt active filter," IEEE Transactions on Industrial Electronics, vol. 56, no. 8, pp. 28112820, 2009.

[13] C. Lascu, L. Asiminoaei, I. Boldea, and F. Blaabjerg, "Frequency response analysis of current controllers for selective harmonic compensation in active power filters," IEEE Transactions on Industrial Electronics, vol. 56, no. 2, pp. 337-347, 2009.

[14] F. D. Freijedo, J. Doval-Gandoy, O. López, P. FernandezComesana, and C. Martinez-Penalver, "A signal-processing adaptive algorithm for selective current harmonic cancellation in active power filters," IEEE Transactions on Industrial Electronics, vol. 56, no. 8, pp. 2829-2840, 2009.

[15] B. Kedjar and K. Al-Haddad, "DSP-based implementation of an LQR with integral action for a three-phase three-wire shunt active power filter," IEEE Transactions on Industrial Electronics, vol. 56, no. 8, pp. 2821-2828, 2009.

[16] L. P. Ling and N. A. Azli, "SVM based hysteresis current controller for a three phase active power filter," in Proceedings of the National Power and Energy Conference (PECon '04), pp. 132-136, Kuala Lumpur, Malaysia, November 2004. 

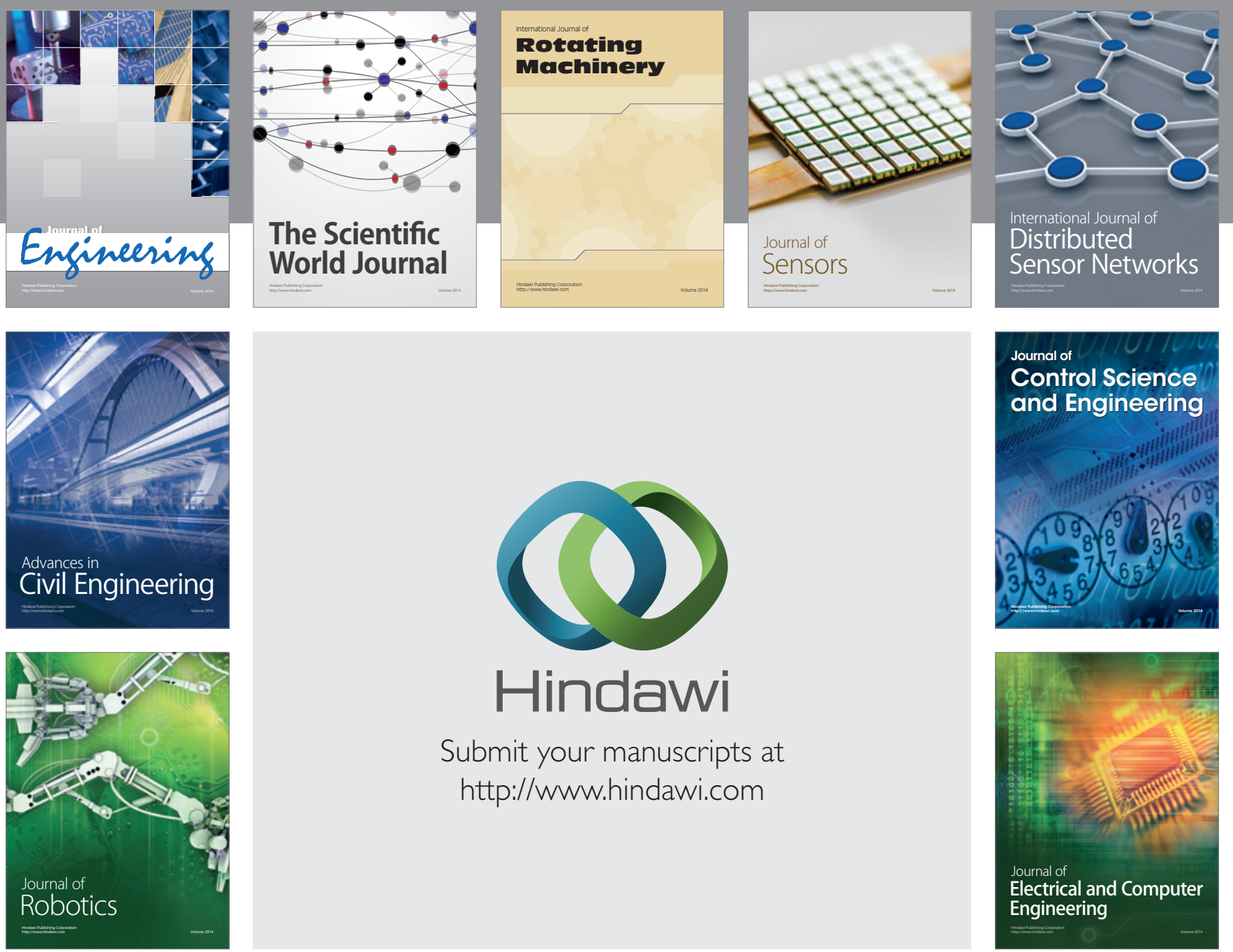

Submit your manuscripts at

http://www.hindawi.com
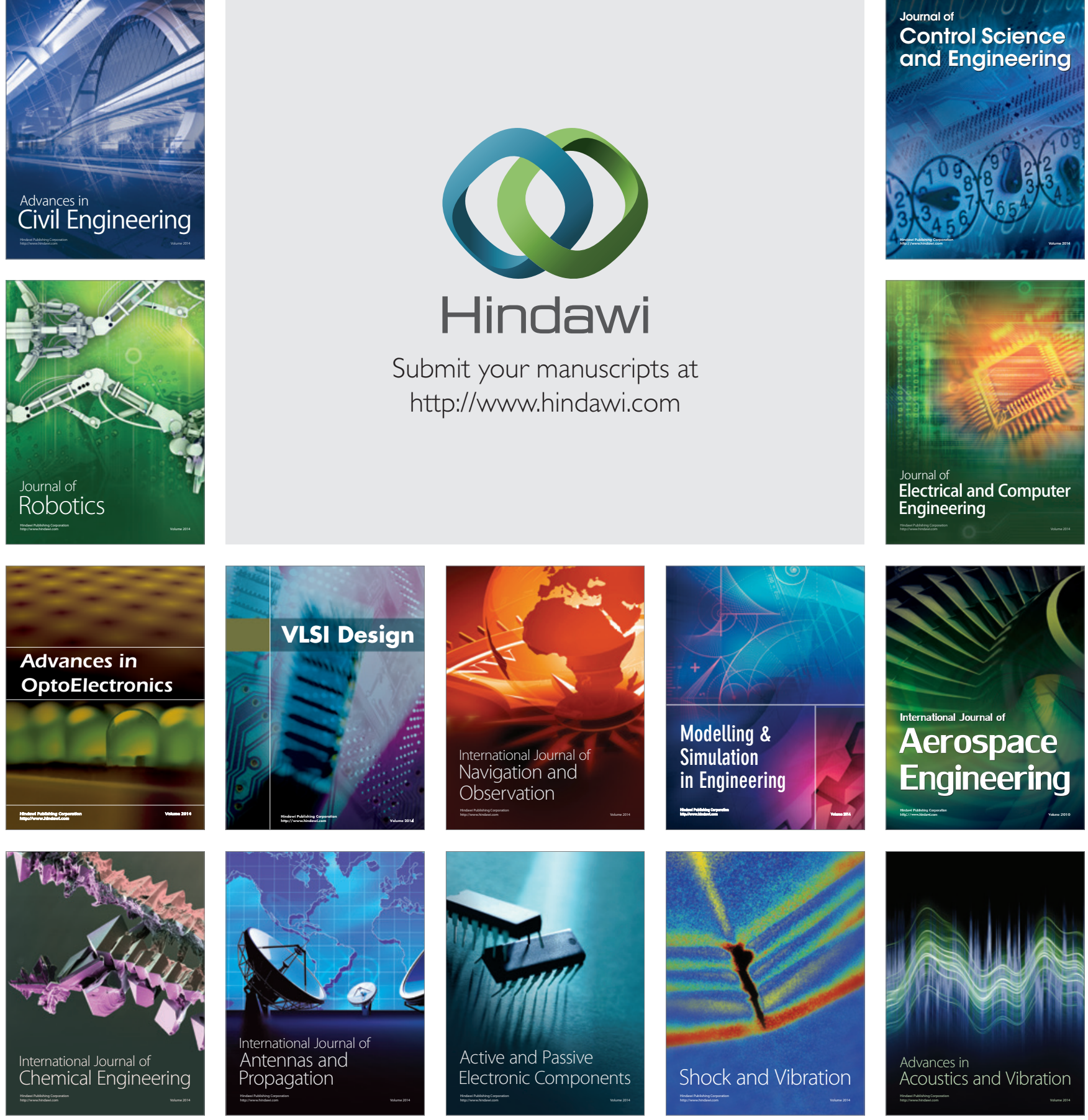